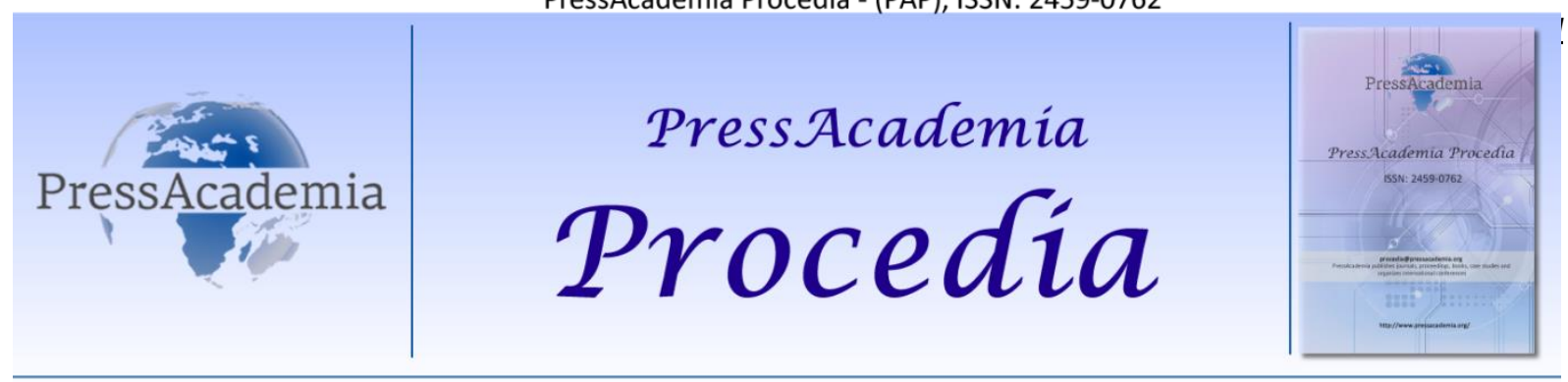

2nd World Conference on Technology, Innovation and Entrepreneurship

May 12-14, 2017, Istanbul, Turkey. Edited by Sefer Şener

\title{
INNOVATIVE SOLAR ENERGY TECHNOLOGY SELECTION USING INTIUTIONISTIC FUZZY SETS
}

\section{DOI: 10.17261/Pressacademia.2017.609 \\ PAP-WCTIE-V.5-2017(47)-p.341-349}

\section{Sezi Cevik Onar ${ }^{1}$, Basar Oztaysi ${ }^{2}$, Cengiz Kahraman ${ }^{3}$}

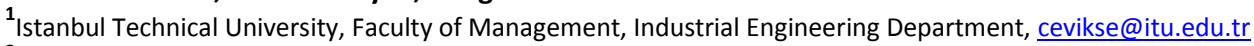

${ }^{2}$ Istanbul Technical University, Faculty of Management, Industrial Engineering Department, oztaysib@itu.edu.tr

${ }^{3}$ Istanbul Technical University, Faculty of Management, Industrial Engineering Department, kahramanc@itu.edu.tr

\begin{abstract}
Solar energy technologies are mainly composed of photovoltaics and concentrated solar power (solar thermal) technologies. Photovoltaic technology converts sunlight into electricity directly whereas solar thermal technology utilizes its heat. Innovative solar energy technologies appear in the market relatively more often than other energy technologies. Selection among these innovative solar energy technologies is a multi-criteria decision making problem under uncertain environment conditions. Intuitionistic fuzzy sets provide an efficient way of capturing uncertainty by processing both membership and non-membership degrees in a set, whose sum of these degrees is not necessarily equal to one. In this paper, we use an interval-valued intuitionistic fuzzy AHP method for the multi-criteria evaluation of some innovative solar energy technologies. An application of solar energy technology selection is also presented through the proposed method.
\end{abstract}

Keywords: Solar energy, innovative technology, fuzzy, intuitionistic fuzzy

\section{INTRODUCTION}

There is an increasing emphasis on renewable sources of energy. Among these renewable energy sources, solar energy is becoming more and more important every day. With the recent developments, it has become one of the main contributors to the total renewable energy installed capacity. Yet, this capacity is still limited when it is compared to the other sources such as fuel or gas. Selecting the appropriate technology can increase the capacity of solar energy.

Solar energy technology selection is a mult-icriteria decision making problem that includes both tangible and intangible criteria which necessities usage of linguistic evaluations. The technology evaluation process contains ambiguity, vagueness and subjectivity in the human judgments.

An intuitionistic fuzzy set has three functions to define it: membership, non-membership, and hesitancy functions. Atanassov and Gargov (1989) proposed interval-valued intuitionistic fuzzy sets (IVIF) where both membership and nonmembership functions are defined as intervals. These sets are considered as a generalization of both interval valued fuzzy sets and intuitionistic fuzzy sets.

In this paper, the steps of interval valued intuitionistic fuzzy AHP method will be given and then it is applied to the technology selection for solar energy. In the literature, difficulty of development, operational efficiency of system, difficulty of capacity expansion, supply stability, possibility of replacing oil energy, popularity of use, impact on related industries, pollution impact, scenic impact, development cost, duration of construction, production cost, size of the technology, and annual production are among the most used criteria for the evaluation of solar energy technologies. We make a multi criteria selection among several solar energy technology alternatives under fuzziness. 


\section{LITERATURE REVIEW}

The solar power technologies have been developed since 19th century. In 1839, French scientist Edmond Becquerel discovered the potential of photovoltaic effect, which later became the main technique for harnessing solar power (U.S. Department of Energy Energy Efficiency and Renewable Energy). In 1954, first silicon photovoltaic cell has been developed and produced with the efficiency of 4\%. Later in $1958 \mathrm{PV}$ panels became the main source of energy for space applications globally. In 1983 worldwide sales of PV cells reached record levels with \$250 Million annually. In 1999, cumulative installed capacity of solar power reached 1GW (U.S. Department of Energy Energy Efficiency and Renewable Energy). Total installed capacity of solar energy reached $177 \mathrm{GW}$ of photovoltaics and $4.4 \mathrm{GW}$ of concentrated solar power systems (Renewable Energy Policy Network for the 21st Century, 2015).

Although solar energy have a long history, in the recent years there is a significant both the generated solar energy capacity and the academic interest on the solar energy. It is possible to understand the year-on-year change for solar energy from the academic databases. A search using the key phrase "Solar Energy" in the "title", "abstract" or "keywords" has been conducted on $18^{\text {th }}$ of April, 2017 on Scopus database. The results are given in Figure 1.

There are mainly two leading Technologies in solar energy, namely, photovoltaic (PV) and concentrated solar power plants (CSP).

\section{Figure 1. Solar Energy Publications}

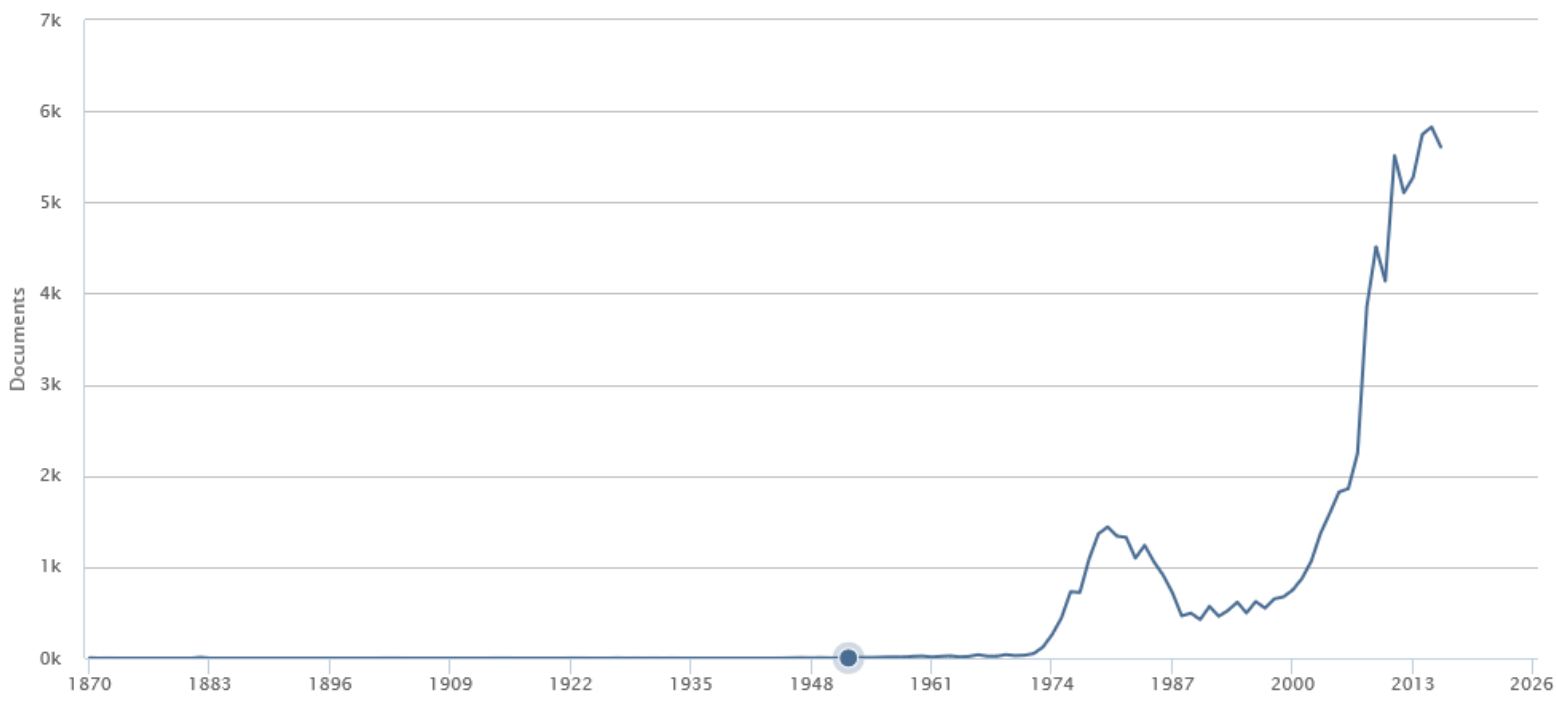

\subsection{Photovoltaic Systems}

Photovoltaic panels are working under a principle of creating a negative charge on a special material (i.e. silicon, Si) with the help of radiance from a sun which results in a voltage which then converted to current of electricity. Efficiency of photovoltaic panels are calculated as a ratio of power output from the cell with the total amount of solar radiance captured on the surface of specified area (Arvizu, et al., 2011).

Important characteristic specifications of a photovoltaic solar panel are the material it has been manufactured and the design of the device. According to Direct Solar Energy report, in 2009, $80 \%$ of the photovoltaic panels in the market were made with CdTe and Thin Film Si while the rest is made with organic absorber materials (Arvizu, et al., 2011).

Phovoltaic systems are consiting of a PV module and balance of system (BOP) components such as; inverter, storage devices, charge controllers etc. It is possible to classify photovoltaic applications depending on their connection to the grid. Additionally consumer related PV applications are also possible but in much smaller scale (Arvizu, et al., 2011).

\subsection{Concentrating Solar Power Systems (CSP)}

Concentrating solar power systems create a high beam of sun light to heat a liquid, gas or solid which later being used in thermal electricity generation. Most of the current electricity generation techniques involve heating or burning materials at 
some point such as gas, nuclear, biomass or oil. This shows that further improvements in the technology of gas and steam turbines will contribute to creating more viable CSP systems (Arvizu, et al., 2011).

Solar collectors are at the heart of any solar power system and it is possible to categorize collectors into two categories; stationary (non-concentrating) and sun-tracking (concentrating) collectors. As the name implies CSP systems are built upon sun-tracking and concentrating solar collectors. These types of collectors are technologically advanced yet costly when compared to its stationary counterparts as a result offers wide array of advantages such as; higher operating temperature and efficiency. Optical instruments are widely used to provide highly concentrated solar beams to receivers which also adds to the overall cost of the CSP system (Barlev, Vidu, \& Stroeve, 2011). Figure 2 shows the criteria used for solar energy technology selection.

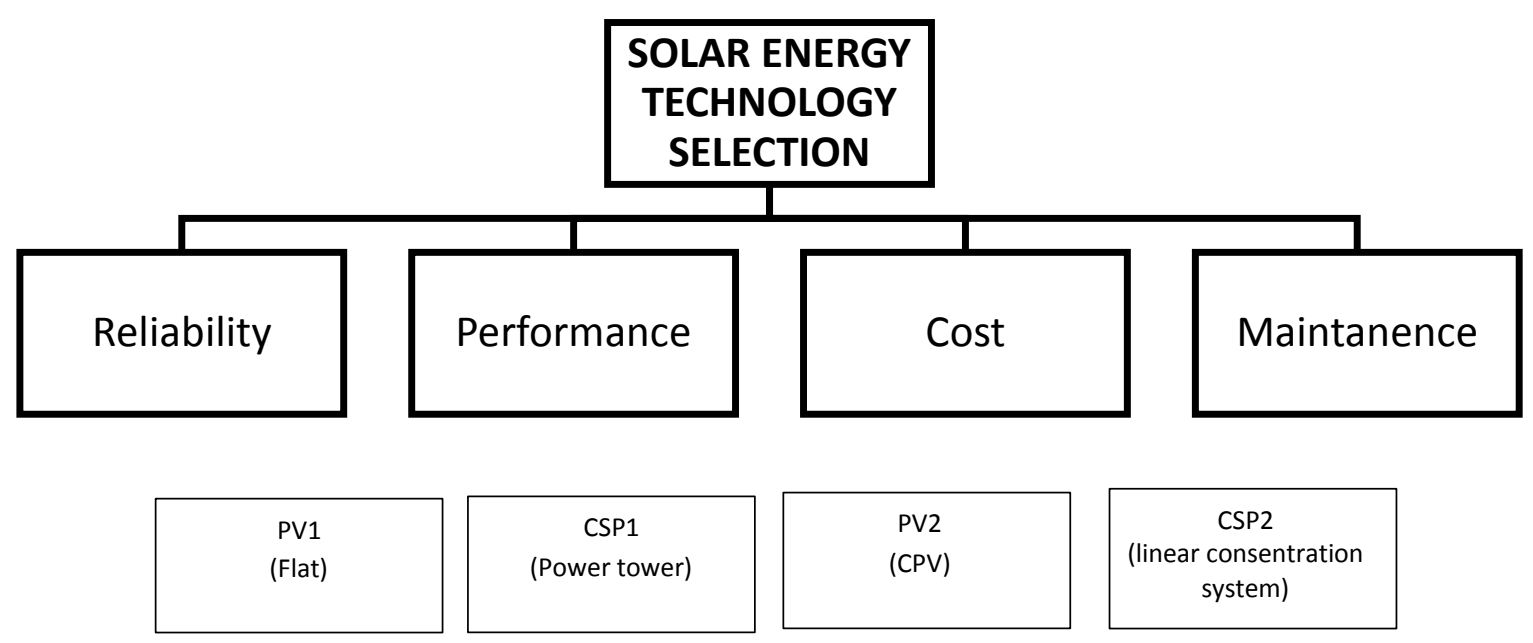

Figure 2: Solar Energy Technology Selection Hierarchy

Reliability covers the issues such as warranty coverage, track record, suitability for environmental conditions such as resistance to extreme weather conditions (Cevik Onar et al., 2015). Performance criterion shows the total energy generation capacity. Cost criterion covers both initial investment costs an operating expenses. The maintanence is the necessity of maintenance activities.

\section{DATA AND METHODOLOGY}

\subsection{Interval Valued Intuitionistic Fuzzy Sets}

An interval-valued intuitionistic fuzzy set in $\widetilde{A}$ over $X$ is defined as follows (Atanassov, 1986):

$\widetilde{\mathrm{A}}=\left\{<\mathrm{x}, \mu_{\widetilde{\mathrm{A}}}(\mathrm{x}), \mathrm{v}_{\widetilde{\mathrm{A}}}(\mathrm{x})>\mid \mathrm{x} \in \mathrm{X}\right\}$,

where

$\mu_{\widetilde{\mathrm{A}}} \rightarrow \mathrm{D} \subseteq[0,1], \mathrm{v}_{\widetilde{\mathrm{A}}}(\mathrm{x}) \rightarrow \mathrm{D} \subseteq[0,1]$

with the condition $0 \leq \sup _{\widetilde{\mathrm{A}}}(\mathrm{x})+\operatorname{supv}_{\widetilde{\mathrm{A}}}(\mathrm{x}) \leq 1, \forall \mathrm{x} \in \mathrm{X}$.

The intervals $\mu_{\widetilde{A}}(x)$ and $v_{\widetilde{A}}(x)$ denote the membership and non-membership functions of the element $x$ to the set $\widetilde{A}$, respectively. Interval-valued Intiutionistic fuzzy set $\widetilde{\mathrm{A}}$ is denoted by

$\widetilde{\mathrm{A}}=\left\{<\mathrm{x},\left[\mu_{\widetilde{\mathrm{A}}}^{-}(\mathrm{x}), \mu_{\widetilde{\mathrm{A}}}^{+}(\mathrm{x})\right],\left[\mathrm{u}_{\widetilde{\mathrm{A}}}^{-}(\mathrm{x}), \mathrm{v}_{\widetilde{\mathrm{A}}}^{+}(\mathrm{x})\right]>\mid \mathrm{x} \in \mathrm{X}\right\}$, 
where

$0 \leq \mu_{\widetilde{\mathrm{A}}}^{+}(\mathrm{x})+\mathrm{v}_{\widetilde{\mathrm{A}}}^{+}(\mathrm{x}) \leq 1, \quad \mu_{\widetilde{\mathrm{A}}}^{\bar{\tau}}(\mathrm{x}) \geq 0, \mathrm{v}_{\widetilde{\mathrm{A}}}^{\overline{(}}(\mathrm{x}) \geq 0$.

Eq. (3) defines the hesitancy degree of an interval-valued intuitionistic fuzzy set of $x \in X$ in $\widetilde{A}$.

$\pi_{\widetilde{\mathrm{A}}}(\mathrm{x})=1-\mu_{\widetilde{\mathrm{A}}}(\mathrm{x})-\mathrm{v}_{\widetilde{\mathrm{A}}}(\mathrm{x})=\left(\left[1-\mu_{\widetilde{\mathrm{A}}}^{+}(\mathrm{x})-\mathrm{v}_{\widetilde{\mathrm{A}}}^{+}(\mathrm{x})\right], 1-\mu_{\widetilde{\mathrm{A}}}^{-}(\mathrm{x})-\mathrm{v}_{\widetilde{\mathrm{A}}}^{-}(\mathrm{x})\right)$

For convenience, let $\mu_{\widetilde{\mathrm{A}}}(\mathrm{x})=\left[\mu_{\widetilde{\mathrm{A}}}^{-}(\mathrm{x}), \mu_{\widetilde{\mathrm{A}}}^{+}(\mathrm{x})\right]=\left[\mu_{\widetilde{\mathrm{A}}}, \mu_{\widetilde{\mathrm{A}}}^{+}\right], v_{\widetilde{\mathrm{A}}}(\mathrm{x})=\left[\mathrm{v}_{\widetilde{\mathrm{A}}}^{-}(\mathrm{x}), v_{\widetilde{\mathrm{A}}}^{+}(\mathrm{x})\right]=\left[\mathrm{v}_{\widetilde{\mathrm{A}}}^{-}, v_{\widetilde{\mathrm{A}}}^{+}\right]$, so $\widetilde{\mathrm{A}}=\left(\left[\mu_{\widetilde{\mathrm{A}}}, \mu_{\widetilde{\mathrm{A}}}^{+}\right],\left[v_{\widetilde{\mathrm{A}}}^{-}\right.\right.$, $\left.\left.v_{\widetilde{A}}^{+}\right]\right)$.

Some arithmetic operations with interval-valued intuitionistic fuzzy numbers and $\lambda \geq 0$ are given in the following. Let $\widetilde{\mathrm{A}}=\left(\left[\mu_{\widetilde{\mathrm{A}}}{ }^{-}, \mu_{\widetilde{\mathrm{A}}}{ }^{+}\right],\left[\mathrm{v}_{\widetilde{\mathrm{A}}}{ }^{-}, \mathrm{v}_{\widetilde{\mathrm{A}}}{ }^{+}\right]\right)$and $\widetilde{\mathrm{B}}=\left(\left[\mu_{\widetilde{\mathrm{B}}}{ }^{-}, \mu_{\widetilde{\mathrm{B}}}{ }^{+}\right],\left[\mathrm{v}_{\widetilde{\mathrm{B}}}{ }^{-}, \mathrm{v}_{\widetilde{\mathrm{B}}}{ }^{+}\right]\right)$be two interval-valued intuitionistic fuzzy numbers. Then,

$\widetilde{\mathrm{A}} \oplus \widetilde{\mathrm{B}}=\left(\left[\mu_{\widetilde{\mathrm{A}}}^{-}+\mu_{\widetilde{\mathrm{B}}}^{-}-\mu_{\widetilde{\mathrm{A}}}^{-} \mu_{\widetilde{\mathrm{B}}}, \mu_{\widetilde{\mathrm{A}}}^{+}+\mu_{\widetilde{\mathrm{B}}}^{+}-\mu_{\widetilde{\mathrm{A}}}^{+} \mu_{\widetilde{\mathrm{B}}}^{+}\right],\left[\mathrm{v}_{\widetilde{\mathrm{A}}}^{\overline{\mathrm{A}}} \mathrm{v}_{\widetilde{\mathrm{B}}}^{-}, \mathrm{v}_{\widetilde{\mathrm{A}}}^{+} \mathrm{v}_{\widetilde{\mathrm{B}}}^{+}\right]\right)$

$\widetilde{\mathrm{A}} \otimes \widetilde{\mathrm{B}}=\left(\left[\mu_{\widetilde{\mathrm{A}}}^{-} \mu_{2}^{-}, \mu_{\widetilde{\mathrm{A}}}^{+} \mu_{2}^{+}\right],\left[\mathrm{v}_{\widetilde{\mathrm{A}}}^{-}+\mathrm{v}_{2}^{-}-\mathrm{v}_{\widetilde{\mathrm{A}}}^{-} \mathrm{v}_{2}^{-}, \mathrm{v}_{\widetilde{\mathrm{A}}}^{+}+\mathrm{v}_{2}^{+}-\mathrm{v}_{\widetilde{\mathrm{A}}}^{+} \mathrm{v}_{2}^{+}\right]\right)$

\subsection{Interval Valued Intuitionistic Fuzzy AHP Method}

The proposed interval valued intuitionistic fuzzy AHP method is given in the following (modified from Wu et al., 2013).

Firsts step is constructing the fuzzy preference relation matrix composed of linguistic terms assigned from Table 2 for the pairwise comparisons of criteria by each expert.

Table 2: Linguistic Scale and Its Corresponding IVIFS

\begin{tabular}{|l|l|}
\hline Linguistic Terms & $\begin{array}{l}\text { Membership \& Non-membership } \\
\text { values }\end{array}$ \\
\hline Absolutely Low (AL) & $([0.10,0.25],[0.65,0.75])$ \\
\hline Very Low (VL) & $([0.15,0.30],[0.60,0.70])$ \\
\hline Low (L) & $([0.20,0.35],[0.55,0.65])$ \\
\hline Medium Low (ML) & $([0.25,0.40],[0.50,0.60])$ \\
\hline Equal (E) & $([0.50,0.50],[0.50,0.50])$ \\
\hline Medium High (MH) & $([0.50,0.60],[0.25,0.40])$ \\
\hline High (H) & $([0.55,0.65],[0.20,0.35])$ \\
\hline Very High (VH) & $([0.60,0.70],[0.15,0.30])$ \\
\hline Absolutely High (AH) & $([0.65,0.75],[0.10,0.25])$ \\
\hline
\end{tabular}

Second step is converting the interval-valued intuitionistic fuzzy preference relation matrix on criteria for each expert.

$$
\tilde{G}_{k}=\left[\begin{array}{ccc}
\tilde{g}_{11}^{(k)} & \cdots & \tilde{g}_{1 p}^{(k)} \\
\vdots & \ddots & \vdots \\
\tilde{g}_{p 1}^{(k)} & \cdots & \tilde{g}_{p p}^{(k)}
\end{array}\right], \mathrm{k}=1,2, \ldots, \mathrm{m}
$$

where $m$ is the number of experts.

Third step is applying the operation in Eq. (6) to aggregate each row of preference relations.

Fourth step is calculating the score judgment matrix $\tilde{\mathrm{S}}=\left(\tilde{\mathrm{S}}_{\mathrm{ij}}\right)_{\mathrm{n} \times \mathrm{n}}$ and the interval multiplicative matrix $\tilde{A}=\left(\tilde{a}_{i j}\right)_{n \times n}$. The score judgment matrix of $\widetilde{R}_{g}$ is represented by the matrix

$$
\tilde{\mathrm{S}}=\left(\tilde{\mathrm{S}}_{\mathrm{ij}}\right)_{\mathrm{n} \times \mathrm{n}}=\left[\mu_{\mathrm{g}_{\mathrm{ij}}}^{-}-v_{\mathrm{g}_{\mathrm{ij}}}^{+}, \mu_{\mathrm{g}_{\mathrm{ij}}}^{+}-v_{\mathrm{g}_{\mathrm{ij}}}^{-}\right] \text {as follows: }
$$




$$
\begin{aligned}
& \tilde{\mathrm{S}}=\left[\begin{array}{ccc}
{\left[\mu_{\mathrm{g}_{11}}^{-}-v_{\mathrm{g}_{11}}^{+}, \mu_{\mathrm{g}_{11}}^{+}-v_{\mathrm{g}_{11}}^{-}\right]} & \cdots & {\left[\mu_{\mathrm{g}_{1 \mathrm{n}}}^{-}-v_{\mathrm{g}_{1 \mathrm{n}}}^{+}, \mu_{\mathrm{g}_{1 \mathrm{n}}}^{+}-v_{\mathrm{g}_{1 \mathrm{n}}}^{-}\right]} \\
\vdots & \ddots & \vdots \\
{\left[\mu_{\mathrm{g}_{\mathrm{n} 1}}^{-}-v_{\mathrm{g}_{\mathrm{n} 1}}^{+}, \mu_{\mathrm{g}_{\mathrm{n} 1}}^{+}-v_{\mathrm{g}_{\mathrm{n} 1}}^{-}\right]} & \cdots & {\left[\mu_{\mathrm{g} n}^{-}-v_{\mathrm{g}_{\mathrm{nn}}}^{+}, \mu_{\mathrm{g} \mathrm{nn}}^{+}-v_{\mathrm{g}_{\mathrm{nn}}}^{-}\right]}
\end{array}\right]
\end{aligned}
$$

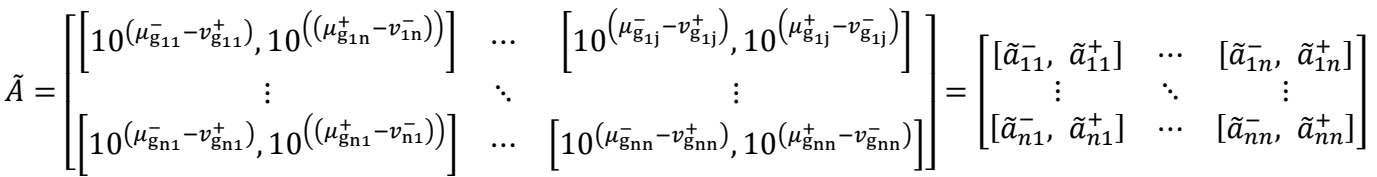

Thus, the score judgment matrix $\tilde{\mathrm{S}}=\left(\tilde{\mathrm{S}}_{\mathrm{ij}}\right)_{\mathrm{n} \times \mathrm{n}}$ is converted to the matrix $\tilde{A}$ whose values are between 0 and 10 .

Fifth step is determining the priority vector of the interval multiplicative matrix $\tilde{A}=\left(\tilde{a}_{i j}\right)_{n \times n}$ by calculating the $\widetilde{w}_{i}$ interval for each criterion using Eq. (9)

$$
\widetilde{w}_{i}=\left[\frac{\sum_{j=1}^{n} \tilde{a}_{i j}^{-}}{\sum_{i=1}^{n} \sum_{j=1}^{n} \tilde{a}_{i j}^{+}}, \frac{\sum_{j=1}^{n} \tilde{a}_{i j}^{+}}{\sum_{i=1}^{n} \sum_{j=1}^{n} \tilde{a}_{i j}^{-}}\right]=\left[w_{i}^{-}, w_{i}^{+}\right], i=1, \ldots, n
$$

Sixth step is constructing the possibility degree matrix $P=\left(p_{i j}\right)_{n \times n}$ by comparing the obtained weights in Step 5. To do this, use Eq. (10):

$$
P\left(w_{i} \geq w_{j}\right)=p_{i j}=\frac{\min \left\{L_{w_{i}}+L_{w_{j}} \max \left(w_{i}{ }^{+}-w_{j}{ }^{-}, 0\right)\right\}}{L_{w_{i}}+L_{w_{j}}}
$$

where $L_{w_{i}}=w_{i}^{+}-w_{i}^{-}$and $L_{w_{j}}=w_{j}^{+}-w_{j}^{-}$and $p_{i j} \geq 0, p_{i j}+p_{j i}=1, p_{i i}=1 / 2$.

Seventh step is prioritizing the $P=\left(p_{i j}\right)_{n \times n}$ by Eq. (11):

$$
w_{i}=\frac{1}{n}\left[\sum_{j=1}^{n} p_{i j}+\frac{n}{2}-1\right]
$$

Eighth step is normalizing the weights vector obtained in Step 7 and obtain the normalized weights $w_{i}^{T}$ of the alternatives, as given by Eq. (12):

$$
w_{i}^{T}=\frac{w_{i}}{\sum_{i=1}^{n} w_{i}}
$$

Ninth step is obtaining the compromised decision matrix from experts, composed of alternatives performances with respect to criteria utilizing Table 2.

$$
\widetilde{D}_{k}=\left[\begin{array}{ccc}
\tilde{d}_{11} & \cdots & \tilde{d}_{1 p} \\
\vdots & \ddots & \vdots \\
\tilde{d}_{p 1} & \cdots & \tilde{d}_{p p}
\end{array}\right]
$$

Then, generate the weighted decision matrix $(\mathrm{P})$ by using the weights of criteria obtained in Step 8.

$\tilde{P}=\widetilde{D}_{k} \times w_{c}$

Obtain the total scores by summing the values in each row and select the alternative with the defuzzified largest score.

Last step is applying sensitivity analyses to check the robustness of the decision against the small changes in the values of problem parameters.

\section{FINDINGS AND DISCUSSIONS}

The proposed R\&D strategy selection model has been applied to solar energy technology selection in Turkey. The planned capacity of the energy generation facility is three megawatts and the land is located in the central Anatolia. There are four solar energy technology alternatives. Two of them are CSP systems. First CSP system is a power tower system and the second CSP system is a linear concentration system. Similarly, two types of photo voltatic (PV) system is under 
considiration. The first PV system is the classical flat-plate system wheras the second PV system is a concentrator photovoltaics (CPV) where lenses and mirrors are used to focus sunlight.

Three experts in the company have individually evaluated the main criteria with respect to the goal, which is to select the best solar energy strategy. These evaluation matrices are given in Table 3.

Table 3: Evaluation Matrices for the Main Criteria

\begin{tabular}{|l|l|l|l|l|}
\hline Criteria & Reliability & Performance & Cost & Maintenance \\
\hline Reliability & EE & MH & ML & VH \\
\hline Performance & & EE & ML & VH \\
\hline Cost & & & EE & AH \\
\hline Maintenance & & & & EE \\
\hline
\end{tabular}

\begin{tabular}{|l|l|l|l|l|}
\hline Criteria & Reliability & Performance & Cost & Maintenance \\
\hline Reliability & EE & MH & E & H \\
\hline Performance & & EE & MH & VH \\
\hline Cost & & & EE & VH \\
\hline Maintenance & & & & EE \\
\hline
\end{tabular}

\begin{tabular}{|l|l|l|l|l|}
\hline Criteria & Reliability & Performance & Cost & Maintenance \\
\hline Reliability & EE & ML & ML & EE \\
\hline Performance & & EE & ML & VH \\
\hline Cost & & & EE & AH \\
\hline Maintenance & & & & EE \\
\hline
\end{tabular}

The evaluations for solar energy technologies with respect to the main criteria are presented in Table 4. 
Table 4: Evaluations for Solar Energy Technologies with Respect to the Main Criteria

wrt Reliability

\begin{tabular}{|l|l|l|l|l|}
\hline Criteria & PV1 & PV2 & CSP1 & CSP2 \\
\hline PV1 & E & MH & H & VH \\
\hline PV2 & & E & MH & MH \\
\hline CSP1 & & & E & MH \\
\hline CSP2 & & & & E \\
\hline
\end{tabular}

\begin{tabular}{|l|l|l|l|l|}
\hline Criteria & PV1 & PV2 & CSP1 & CSP2 \\
\hline PV1 & E & E & MH & MH \\
\hline PV2 & & E & MH & MH \\
\hline CSP1 & & & E & E \\
\hline CSP2 & & & & E \\
\hline
\end{tabular}

\begin{tabular}{|l|l|l|l|l|}
\hline Criteria & PV1 & PV2 & CSP1 & CSP2 \\
\hline PV1 & E & VH & H & VH \\
\hline PV2 & & E & L & ML \\
\hline CSP1 & & & E & H \\
\hline CSP2 & & & & E \\
\hline
\end{tabular}

wrt Cost
\begin{tabular}{|l|l|l|l|l|}
\hline Criteria & PV1 & PV 2 & CSP1 & CSP2 \\
\hline PV1 & E & VH & MH & AH \\
\hline PV2 & & E & L & ML \\
\hline CSP1 & & & E & MH \\
\hline CSP2 & & & & E \\
\hline
\end{tabular}

\begin{tabular}{|l|l|l|l|l|}
\hline Criteria & PV1 & PV2 & CSP1 & CSP2 \\
\hline PV1 & E & MH & MH & VH \\
\hline PV2 & & E & E & MH \\
\hline CSP1 & & & E & E \\
\hline CSP2 & & & & E \\
\hline
\end{tabular}

\begin{tabular}{|l|l|l|l|l|}
\hline Criteria & PV1 & PV2 & CSP1 & CSP2 \\
\hline PV1 & E & MH & VH & AH \\
\hline PV2 & & E & MH & MH \\
\hline
\end{tabular}

wrt Performance

\begin{tabular}{|l|l|l|l|l|}
\hline Criteria & PV1 & PV2 & CSP1 & CSP2 \\
\hline PV1 & $\mathrm{E}$ & $\mathrm{ML}$ & $\mathrm{ML}$ & $\mathrm{ML}$ \\
\hline PV2 & & $\mathrm{E}$ & $\mathrm{ML}$ & $\mathrm{ML}$ \\
\hline CSP1 & & & $\mathrm{E}$ & $\mathrm{MH}$ \\
\hline CSP2 & & & & $\mathrm{E}$ \\
\hline
\end{tabular}

\begin{tabular}{|l|l|l|l|l|}
\hline Criteria & PV1 & PV2 & CSP1 & CSP2 \\
\hline PV1 & E & ML & L & L \\
\hline PV2 & & E & ML & ML \\
\hline CSP1 & & & E & E \\
\hline CSP2 & & & & E \\
\hline
\end{tabular}

\begin{tabular}{|l|l|l|l|l|}
\hline Criteria & PV1 & PV2 & CSP1 & CSP2 \\
\hline PV1 & E & VL & L & AL \\
\hline PV2 & & E & MH & L \\
\hline CSP1 & & & E & L \\
\hline CSP2 & & & & E \\
\hline
\end{tabular}

wrt maintenance
\begin{tabular}{|l|l|l|l|l|}
\hline Criteria & PV1 & PV 2 & CSP1 & CSP2 \\
\hline PV1 & E & MH & H & H \\
\hline PV2 & & E & MH & MH \\
\hline CSP1 & & & E & VH \\
\hline CSP2 & & & & E \\
\hline
\end{tabular}

\begin{tabular}{|l|l|l|l|l|}
\hline Criteria & PV1 & PV2 & CSP1 & CSP2 \\
\hline PV1 & E & MH & MH & MH \\
\hline PV2 & & E & MH & E \\
\hline CSP1 & & & E & E \\
\hline CSP2 & & & & E \\
\hline
\end{tabular}

\begin{tabular}{|l|l|l|l|l|}
\hline Criteria & PV1 & PV2 & CSP1 & CSP2 \\
\hline PV1 & E & MH & H & H \\
\hline PV2 & & E & H & E \\
\hline
\end{tabular}



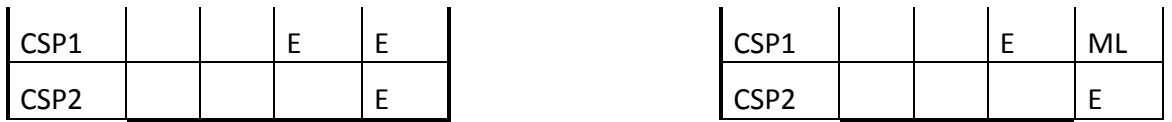

Table 5 summarizes the aggregated TIFN evaluations and the defuzzified weights of the main criteria.

Table 5: Aggregated TIFN Evaluations and the Defuzzified Weights

\begin{tabular}{|l|l|l|l|l|l|}
\hline & Reliability & Performance & Cost & Maintenance & weight \\
\hline Reliability & $(0.5,0.5,0.5,0.5)$ & $(0.43,0.54,0.31,0.46)$ & $(0.34,0.44,0.5,0.56)$ & $(0.55,0.63,0.25,0.37)$ & 0.266 \\
\hline Performance & $(0.34,0.48,0.4,0.52)$ & $(0.5,0.5,0.5,0.5)$ & $(0.34,0.48,0.4,0.52)$ & $(0.6,0.7,0.15,0.3)$ & 0.287 \\
\hline Cost & $(0.5,0.57,0.31,0.43)$ & $(0.43,0.54,0.31,0.46)$ & $(0.5,0.5,0.5,0.5)$ & $(0.65,0.73,0.11,0.27)$ & 0.322 \\
\hline Maintenance & $(0.3,0.39,0.55,0.61)$ & $(0.15,0.3,0.6,0.7)$ & $(0.12,0.27,0.63,0.73)$ & $(0.5,0.5,0.5,0.5)$ & 0.125 \\
\hline
\end{tabular}

Cost is the most important criteria whereas maintenance is the least important criteria for the solar energy investment decision. Table 6 gives the scores of solar energy technologies with respect to the main criteria. The total score of the alternatives are also given in this Table. According to the results, although it shows the lowest performance classical flatplate system (PV1) gets the highest score due to its cost advantage. A decrease in the cost of the other technologies will have a significant impact on the solar energy technology selection.

Table 6: Scores of Solar Energy Technologies with respect to the Criteria

\begin{tabular}{|c|c|c|c|}
\hline Main Criteria & Alternatives & Local score & Global score \\
\hline \multirow{4}{*}{ Reliability (0.266) } & PV1 & 0.347 & 0.093 \\
\hline & $\mathrm{PV} 2$ & 0.240 & 0.064 \\
\hline & CSP1 & 0.239 & 0.064 \\
\hline & CSP2 & 0.174 & 0.046 \\
\hline \multirow{4}{*}{ Performance $(0.287)$} & PV1 & 0.137 & 0.039 \\
\hline & PV2 & 0.254 & 0.073 \\
\hline & CSP1 & 0.289 & 0.083 \\
\hline & CSP2 & 0.319 & 0.092 \\
\hline \multirow{4}{*}{ Cost $(0.304)$} & PV1 & 0.369 & 0.119 \\
\hline & PV2 & 0.224 & 0.072 \\
\hline & CSP1 & 0.227 & 0.073 \\
\hline & $\mathrm{CSP} 2$ & 0.180 & 0.058 \\
\hline \multirow{4}{*}{ Maintenance $(0.125)$} & PV1 & 0.346 & 0.043 \\
\hline & PV2 & 0.270 & 0.034 \\
\hline & CSP1 & 0.202 & 0.025 \\
\hline & CSP2 & 0.181 & 0.023 \\
\hline
\end{tabular}

\begin{tabular}{|l|r|}
\hline & Total Score \\
\hline PV1 & 0.294 \\
\hline PV2 & 0.242 \\
\hline CSP1 & 0.245 \\
\hline CSP2 & 0.219 \\
\hline
\end{tabular}

In order to check the robustness of the model, we conduct a sensitivity analysis based on the performance main criteria. Figure 3 illustrates the results of the sensitivity analysis. This shows that increasing the importance of the performance criteria changes the results. When the performance becomes very important CSP2 is a better alternative for this area. 
Figure 3: Sensitivity Analysis with respect to Performance Criteria Weight

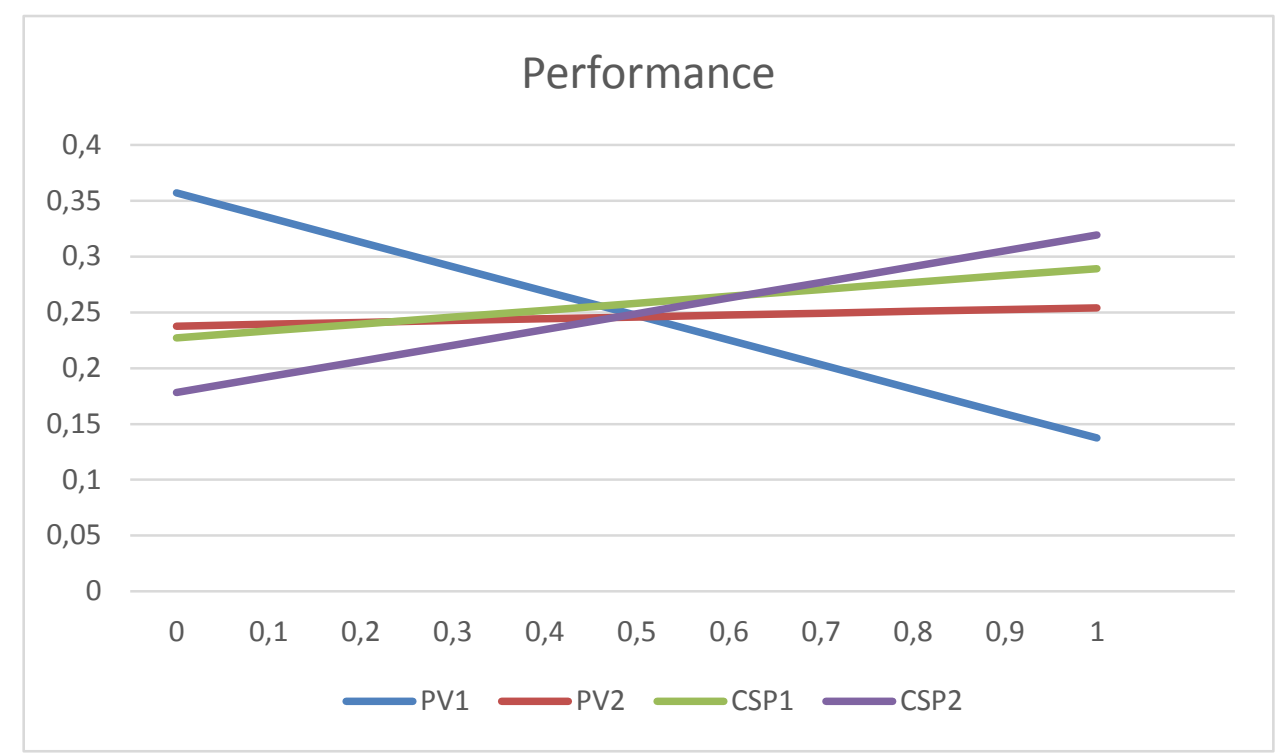

\section{CONCLUSION}

Innovative solar energy technologies should be evaluated by using a multi-criteria decision making method, which can be handle linguistic evaluations under uncertainty. Innovativeness requires new criteria to be used in the evaluation process and causes a harder evaluation process because of uncertainty conditions of new technologies. The proposed method can consider these uncertainties through intuitionistic fuzzy sets. AHP based IVIF multi-criteria method successfully evaluated the solar energy technologies. Consistency of the pairwise comparison matrices and sensitivity of the given decisions have been examined. The obtained results are consistent and robust.

For further research, other extensions of fuzzy sets such as hesitant fuzzy sets, type-2 fuzzy sets, or neutrosophic fuzzy sets can be used in the proposed method for comparison purposes.

\section{REFERENCES}

Atanassov K.T. (1986), Intuitionistic Fuzzy Sets, Fuzzy Sets and Systems, 20, 87-96, Elsevier.

U.S. Department of Energy Energy Efficiency and Renewable Energy. (n.d.). The History of Solar.

Renewable Energy Policy Network for the 21st Century. (2015). Renewables 2015, Global Status Report. Paris.

U.S. Department of Energy Energy Efficiency and Renewable Energy. (n.d.). The History of Solar.

Arvizu, D., Balaya , P., Luisa, C. F., Hollands, K. T., Jager-Walnau, A., Kondo, M., . . Zilles, R. (2011). Special Report on Renewable Energy Resources and Climate Change Mitigation. Intergovernmental Panel on Climate Change. Cambridge University Press.

Barlev, D., Vidu, R., \& Stroeve, P. (2011, May). Innovation in concentrated solar power. Solar Energy Materials \& Solar Cells, 95, $2703-2725$.

Wu, J., Huang, H.-B., and Cao,Q.-W. (2013). Research on AHP with interval-valued intuitionistic fuzzy sets and its application in multi-criteria decision making problems, Applied Mathematical Modelling, 37, 9898-9906. 